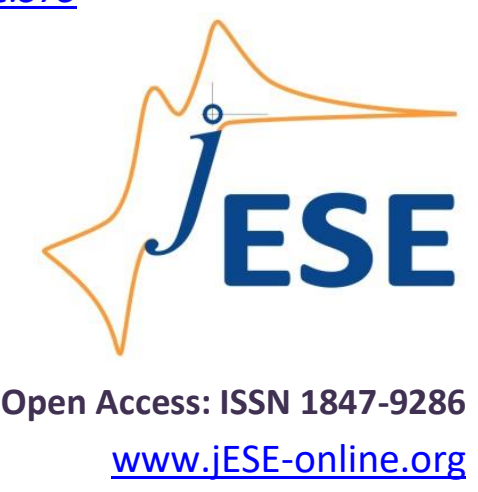

Original scientific paper

\title{
Potentiometric detection of low-levels of sulfamethazine in milk and pharmaceutical formulations using novel plastic membrane sensors
}

\author{
Saad S. M. Hassan ${ }^{\bowtie}$, Ayman H. Kamel ${ }^{\Xi}$, Nada H. A. Elbehery \\ Chemistry Department, Faculty of Science, Ain Shams University, Cairo, Egypt \\ Corresponding authors E-mail: ${ }^{凶}$ saadsmhassan@yahoo.com; ${ }^{\circledR}$ ahkamel76@sci.asu.edu.eg
}

Received: June13, 2018; Revised: July 29, 2018; Accepted: July 30, 2018

\begin{abstract}
Novel potentiometric sensors for selective screening of sulfamethazine (SMZ) in pharmaceutical preparations and milk samples were reported. The sensor membranes were made from PVC matrix doped with magnesium(II)-, manganese(II)- and dichlorotin (IV)-phthalocyanines as ionophores and aliquat-336 and nitron/SMZ ion-pair complex as ion exchangers. These sensors revealed fast, stable and near-Nernstian anionic response for the singly charged sulfamethazine anion over the concentration range $10^{-2}-10^{-5} \mathrm{M}$. The sensors exhibited good selectivity towards SMZ over most known anions, excipients and diluents commonly added in drug preparations. Validation of the proposed methods was demonstrated via evaluating the detection limit, linear response range, accuracy, precision (within-day repeatability) and between-day-variability. The sensors were easily interfaced with a double channel flow injection system and used for continuous monitoring of SMZ in drug formulations, spiked milk samples and biological tissues. The method offers the advantages of design simplicity, results accuracy, and automation feasibility.
\end{abstract}

\section{Keywords}

Sulfamethazine; potentiometric-ion sensors; automation; method validation

\section{Introduction}

Sulphonamides are classified and managed as antimicrobials for the treatment of food-producing animals such as cattle, sheeps, pigs and poultry [1,2]. Side effects are correlated with high quantities of antibiotic residues in edible tissues such as resistance of microorganisms to antibiotic treatment, toxicological hazards, and allergenic effects [3]. For food safety, the maximum allowable quantities determined by the European community for sulfonamides in meat food products and milk is $100 \mu \mathrm{g} / \mathrm{L}$ [4]. Sulphamethazine (SMZ) (also known as sulfadimidine, SDM) is an example of sulphon- 
amides, a broad-spectrum antibiotic used for the treatment of gastrointestinal and respiratory tract infections in livestocks. SMZ is categorized as a bacteriostatic drug which is very helpful for treatment of bacterial diseases in humans and other species caused by gram positive and gram negative bacteria [5]. It is widely used in veterinary practice for the treatment of coccidiosis in laying hens at the dose of $2 \mathrm{~g} / \mathrm{L}$ for 6 consecutive days via the drinking water [6]. It is also used for therapeutic, prophylactic or as growth promoter and halt the growth of bacteria in animal production $[3,7]$. Meat containing residual of SMZ can result in development drug resistance and hypersensitivity [8]. It has been reported that $S M Z$ is the major issue in testing veterinary animal's feeds. Therefore, analytical methods are needed for detecting and quantification of SMZ residues in food animal products and pharmaceutical formulations. Several methods have been reported for SMZ determination. These methods include colorimetry [9], immunoassay [1,10-13], gas chromatography [14-17], high performance liquid chromatography [18-22], thin layer chromatography [23], liquid chromatography [25-29], microbiological diffusion assay [29], microtitre plate assay [30], indirect atomic absorption spectrometry [31], ratiometric fluorescence with carbon and quantum dots [32], voltammetry [33], potentiometric sensors [34], piezoelectric sensors [35] and transmittance near infrared spectrometry [36].

Most of these methods, however, have several drawbacks due to too long time consumption, labor-intensive effort and expensive cost. Some of these methods need sophisticated instrumentation, suffer from a lack of selectivity, cover a narrow concentration range and need several manipulation steps for preparation and assessment procedures. On the other hand, potentiometric sensors are considered as viable and simple tools and have been used for the analysis of many types of pharmaceuticals [31-34]. These sensors have usually good performance characteristics and display useful analytical features [35-38]. However, little is known about their use for quantification of sulfamethazine.

In the present work, novel potentiometric sensors are proposed for determination of SMZ. Sensors are based on doping PVC membranes with ion exchangers and metal phthalocyanines. Aliquat-336 and nitron ion association complexes with SMZ and charged $\mathrm{Mn}$ (II), $\mathrm{Mg}$ (II) and $\mathrm{Sn}$ (IV) phthalocyanine ionophores are also used as sensing materials. These electroactive materials were dispersed in plasticized PVC membranes and used for static and hydrodynamic measurements of SMZ. The sensors were incorporated in a double channel flow injection system and used for continuous determination of SMZ in cow milk, chicken tissues and pharmaceutical formulations.

\section{Experimental}

\section{Reagents and solutions}

Analytical reagent grade chemicals were used in this work and de-ionized water (conductivity $<0.1 \mu \mathrm{S} / \mathrm{cm}$ ) was employed for solutions preparation. High molecular weight polyvinyl chloride (PVC), o-nitrophenyloctylether (o-NPOE), magnesium (II)-, manganese (II)- and dichlorotin (IV)- phthalocyanines, aliquat-336, tridodecyl-methylammonium chloride (TDMAC) and tetrahydrofuran (THF) were obtained from Fluka (Ronkonoma, NY). Nitron was purchased from Riedel-de Haën. Pure grade of sodium sulfamethazine was obtained from Sigma Aldrich.

$10^{-2} \mathrm{M}$ nitron solution was prepared by dissolving the appropriate solid amount in $20 \%$ acetic acid solution. $20 \mathrm{~mL}$ of $10^{-2} \mathrm{M}$ nitron solution and $10 \mathrm{~mL}$ of $10^{-2} \mathrm{M} \mathrm{SMZ}$ were mixed together and stirred for $15 \mathrm{~min}$. A brown precipitate is formed, filtered off, washed with de-ionized water, dried at room temperature and ground to a fine powder. The elemental analysis agreed with the composition $\left[\mathrm{C}_{20} \mathrm{H}_{17} \mathrm{~N}_{4}^{+}\right]\left[\mathrm{C}_{13} \mathrm{H}_{13} \mathrm{~N}_{3} \mathrm{~S}\right.$ ] that confirms (1:1) stoichiometric ratio. Stock solution of $10^{-1} \mathrm{M}$ 
SMZ was prepared in de-ionized water. Less concentrated SMZ standards were accurately prepared by dilution of the stock solution with a fresh $0.01 \mathrm{M} \mathrm{Na}_{2} \mathrm{SO}_{4}$ solution at $\mathrm{pH}$ 7. Effect of interfering species was evaluated using $10^{-2} \mathrm{M}$ solutions of sodium salts of phosphate, citrate, chloride, thiocyanate, salicylate, iodide, ascorbate, oxalate, tartrate and acetate.

\section{Apparatus}

All potentiometric measurements were done with the electrochemical cell $\mathrm{Ag} / \mathrm{AgCl}$ double junction reference electrode/sample test solution/SMZ selective membrane $/ 10^{-3} \mathrm{M} \mathrm{SMZ}+10^{-3} \mathrm{M}$ of $\mathrm{NaCl} / \mathrm{AgCl} / \mathrm{Ag}$. An Orion, 90-00-29, double junction electrode filled with $0.1 \mathrm{M}$ lithium acetate in its outer compartment was used. Potential differences between indicator and reference electrodes were measured by an Orion digital $\mathrm{pH} / \mathrm{mV}$ meter (type SA 720). The potentiometric signal output was transferred to a replacement point with six ways out; therefore, six sensors readings outplace in the same solution can be achieved. Each way represented an electrical connector that provided suitable adaptation to each sensor. The $\mathrm{pH}$ was measured by a Ross glass $\mathrm{pH}$ combination electrode (Orion 81-02). Spectrophotometric assays were carried out on a Thermo scientific UV/VIS Evolution 300.

\section{Sensor construction and electromotive force (EMF) measurements}

Three milligrams of metal-phthalocyanine ionophores were mixed with $126.4 \mathrm{mg}$ of o-NPOE plasticizer, $64.5 \mathrm{mg}$ PVC and $1.2 \mathrm{mg}$ TDMAC and dissolved in $3 \mathrm{~mL}$ THF. The mixture was poured in a glass Petri dish ( $3 \mathrm{~cm}$ diameter). A membrane consisting of nitron/SMZ ion-pair complex or aliquat336 was prepared by mixing $3 \mathrm{mg}$ of the complex, $125.5 \mathrm{mg}$ of $o-N P O E$ and $65.4 \mathrm{mg}$ PVC. The mixture was dissolved in $3 \mathrm{~mL}$ THF and also poured in a glass Petri dish. The cocktail solutions in Petri dishes were left to evaporate overnight at room temperature to form thin plastic membranes. The membranes were removed and discs were cut out and glued into PVC body using THF. A mixture of $10^{-3} \mathrm{M}$ of SMZ and $10^{-3} \mathrm{M}$ of $\mathrm{NaCl}$ was used as an internal reference solution and $\sim 3 \mathrm{~mm}$ diameter $\mathrm{Ag} / \mathrm{AgCl}$ coated wire was employed as an internal reference electrode. Conditioning of the sensors was performed by soaking overnight in $10^{-4} \mathrm{M} \mathrm{SMZ}$ solution. The sensors were stocked in the same solution when they are not used.

The SMZ sensors were calibrated by immersing them in conjunction with the reference electrode in a $25 \mathrm{~mL}$ beaker containing $10 \mathrm{~mL}$ of $10^{-2} \mathrm{M} \mathrm{Na}_{2} \mathrm{SO}_{4}$ solution of $\mathrm{pH} 7$ as an ionic strength adjustor. Portions $(0.5-1.0 \mathrm{~mL})$ of $10^{-4}-10^{-1} \mathrm{M}$ standard $\mathrm{SMZ}$ solutions were successively added and the potential response of stirred solutions was measured after stabilization to $\pm 0.5 \mathrm{mV}$. A calibration graph was drawn by the EMF readings put against the logarithm of SMZ concentrations. From the linear part of the obtained curve, the quantification of unknown concentrations of sulfamethazine drug can be obtained.

\section{Flow injection setup and measurements}

A home-made tubular detector for SMZ was constructed as described previously [39]. The sensor was conditioned in $10^{-3} \mathrm{M}$ aqueous $\mathrm{SMZ}$ solution for $24 \mathrm{~h}$ and was stored in the same solution when not used. A carrier solution consisting of $10^{-2} \mathrm{M} \mathrm{Na}_{2} \mathrm{SO}_{4}$ of $\mathrm{pH} 7$ was propelled by means of a peristaltic pump through PTEE tubing $(1.13 \mathrm{~mm})$. The sample loop $(100 \mu \mathrm{L})$ of the injection valve was filled and the valve was rotated to allow the sample to be transferred by $10^{-2} \mathrm{M} \mathrm{Na}_{2} \mathrm{SO}_{4}$ stream $(\mathrm{pH} 7)$ to the flow with rate $3.5 \mathrm{~mL} / \mathrm{min}$. The potential outputs were recorded using data acquisition (eight-channel electrode-computer interface (Nico-2000 Ltd., London, UK) controlled by Nico-2000 software). 


\section{Analytical applications}

Some commercially available sulphadimidine injection solutions containing $0.333 \mathrm{~g} \mathrm{SMZ} / \mathrm{mL}$ were analyzed. The vial contents were dispersed in water by sonication and diluted with $0.01 \mathrm{M}$ $\mathrm{Na}_{2} \mathrm{SO}_{4}$ to bring the concentration within the linear calibration range.1.0 $\mathrm{mL}$ aliquots of fresh cow milk samples were spiked with $9.0 \mathrm{~mL}$ aliquots of $0.5-10.0 \mu \mathrm{g} \mathrm{SMZ} / \mathrm{mL}$ in $0.01 \mathrm{M} \mathrm{Na} \mathrm{SO}_{4}$ of $\mathrm{pH}$ 7.0. The mixture was thoroughly homogenized in $15 \mathrm{~mL}$ screw capped falcon centrifuge tubes and sonicated for a period of $5 \mathrm{~min}$ to ensure convenient drug extraction. The potential readings were measured as previously described using SMZ sensors. The potential readings were recorded after equilibrium (10-20 s) and compared with the calibration plot.

Portions (1.0 g) of chicken muscles were homogenized and fortified with $5000 \mu \mathrm{g} / \mathrm{mL} \mathrm{SMZ}$ standard solution to give levels of $0.5,0.75,1.0$ and $2.0 \mu \mathrm{g} / \mathrm{mL}$ of SMZ. The spiked chicken samples were extracted with $3 \mathrm{~mL}$ of acetonitrile/water mixture $(80: 20, \mathrm{v} / \mathrm{v})$ for $30 \mathrm{~min}$ at room temperature with continuous shaking. The sample mixture were centrifuged, filtered and dried under a steady flow of dry nitrogen gas. The residue was re-dissolved in $10 \mathrm{~mL}$ of $0.01 \mathrm{M} \mathrm{Na}_{2} \mathrm{SO}_{4}$ of $\mathrm{pH} 7.0$.

\section{Results and discussion}

\section{Sensors characteristics}

Nitron, aliquat-336 and metal-phthalocyanines were utilized as sensing materials for sulfamethazine (Fig. 1). The structure of these compounds form 1:1 complexes with SMZ as confirmed by elemental analysis and infrared spectrometry.
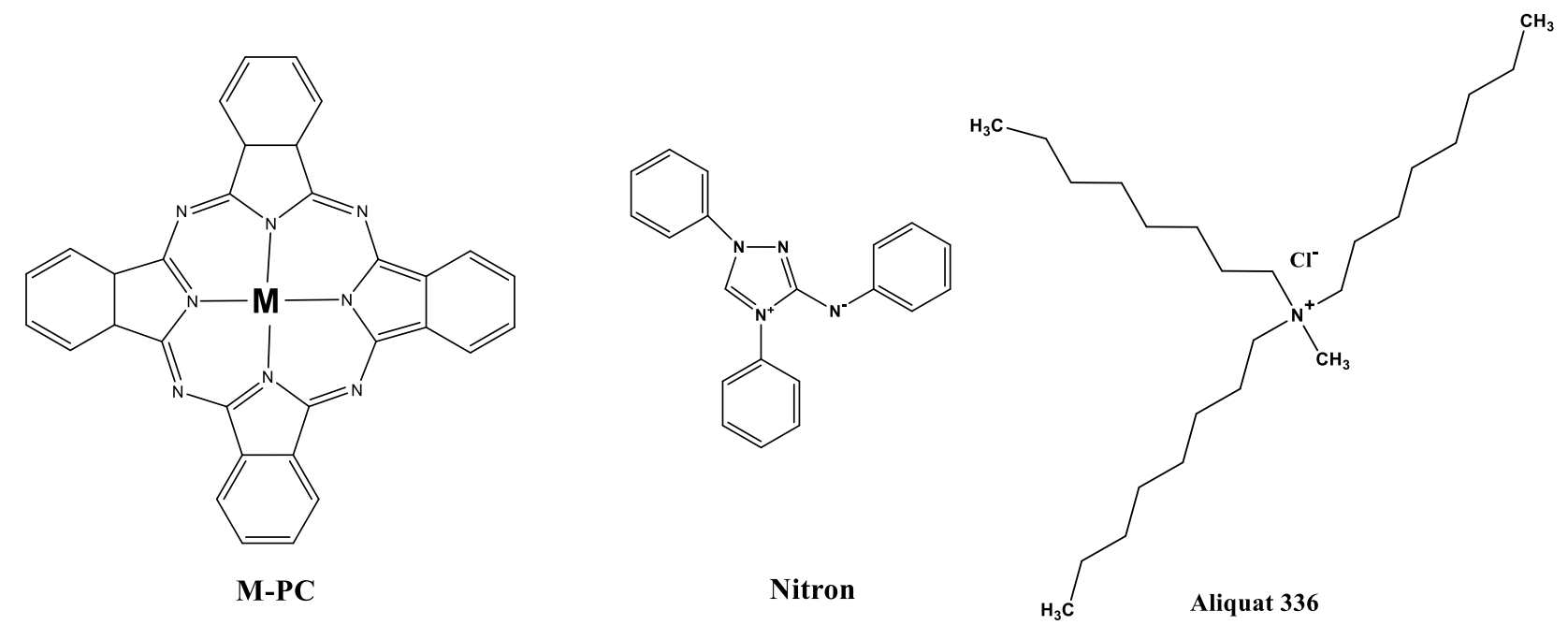

Figure1. Structure of the proposed electroactive materials used for construction of sulfamethazine membrane sensors

Liquid-contact potentiometric sensors were constructed. The membrane sensors were prepared by incorporating $1.5 \mathrm{wt} \%$ of the sensing material in plasticized PVC matrix (33.6 wt\% PVC and 64.4 wt\% o-NPOE solvent mediator). The sensors were tested and electrochemically evaluated at $25 \pm 1{ }^{\circ} \mathrm{C}$ according to the reported recommendations of IUPAC [40]. A cationic additive consisting of $0.5 \mathrm{wt} \%$ TDMAC was added to membranes containing metal-phthalocyanines. The response features of these sensors are shown in Table 1. It can be noticed that sensors with a membrane incorporating nitron/SMZ and aliquat-336 show calibration slopes of $-41.7 \pm 0.6$ and $-63.9 \pm 0.8 \mathrm{mV} /$ decade over the linear concentration range $7.76 \times 10^{-6}-10^{-2}$ and $1.38 \times 10^{-5}-10^{-2} \mathrm{M}$ with lower detection limits of 0.86 and $1.36 \mu \mathrm{g} / \mathrm{mL}$, respectively. Sensors based on metal phthalocyanines (MgPC, MnPC and SnPC), in the presence of TDMAC as a cationic additive, exhibit calibration slopes of $-65.3 \pm 0.4,-80.1 \pm 0.4$ and 
$-69.9 \pm 0.6 \mathrm{mV} /$ decade over the linear concentration ranges $4.8 \times 10^{-6}-10^{-2}, 2.6 \times 10^{-6}-10^{-2}$ and $7.9 \times 10^{-}$ ${ }^{6}-10^{-2} \mathrm{M}$ with detection limits of $0.55,0.4$ and $0.8 \mathrm{\mu g} / \mathrm{mL}$, respectively. Other performance characteristics of all investigated sensors are also presented in Table 1.

The time required for MgPC, MnPC and SnPC based membrane sensors to reach values within \pm 1 $\mathrm{mV}$ of the final equilibrium potential after immersion in SMZ solutions, each having a 10-fold difference in concentration, varies from $10 \mathrm{~s}$ for $>10^{-3} \mathrm{M}$ to $30 \mathrm{~s}$ for $<10^{-3} \mathrm{M} \mathrm{SMZ}$. Nitron/SMZ and aliquat-336 based sensors showed a response time of $20-30 \mathrm{~s}$ for $10^{-3}-10^{-5} \mathrm{M}$. All the membrane sensors exhibit a day-to-day reproducibility of better than $0.6 \mathrm{mV}$ for $10^{-2}-10^{-5} \mathrm{M} \mathrm{SMZ}$ solutions.

\section{Method validation}

Validation of the proposed potentiometric methods for SMZ assessment was made by systematic measuring of the response range, lower detection limit (LOD), accuracy (recovery), precision ( $r$ ), within-day repeatability $\left(\mathrm{CV}_{\mathrm{w}}\right)$, between day-variability $\left(\mathrm{CV}_{\mathrm{b}}\right)$, linearity (correlation coefficient) and sensitivity (slope) over a period of 6 months. The results obtained on six batches (six determinations each) using the quality assurance standards [41] are depicted in Table 1. These data support the application of the proposed new sensors for quality control assessment of drug formulations.

Table 1. Performance characteristics of SMZ membrane sensors in $10^{-2} \mathrm{M} \mathrm{Na}_{2} \mathrm{SO}_{4}$ solution at $\mathrm{pH} 7.0$

\begin{tabular}{lccccc} 
& \multicolumn{5}{c}{ Sensor } \\
\cline { 2 - 6 } Parameter & MgPC & MnPC & SnPC & Aliquat-336 & Nitron/SMZ \\
\hline Slope, mV/decade & $-65.3 \pm 0.4$ & $-80.1 \pm 0.4$ & $-69.9 \pm 0.6$ & $-63.9 \pm 0.8$ & $-41.7 \pm 0.6$ \\
Correlation coefficient $(r)$ & -0.9996 & -0.999 & -0.999 & -0.994 & -0.999 \\
Linear range, $\mathrm{M}$ & $4.78 \times 10^{-6}-10^{-2}$ & $2.63 \times 10^{-6}-10^{-2}$ & $7.94 \times 10^{-6}-10^{-2}$ & $1.38 \times 10^{-5}-10^{-2}$ & $7.76 \times 10^{-6}-10^{-2}$ \\
Detection limit, $\mu \mathrm{g} / \mathrm{mL}$ & 0.55 & 0.40 & 0.80 & 1.36 & 0.86 \\
pH working range, & 7 & 7 & 7 & $6.5-8$ & $6.5-8$ \\
Response time for $10^{-3} \mathrm{M}, \mathrm{s}$ & $\mathrm{ca.10}$ & $\mathrm{ca.10}$ & $\mathrm{ca.10}$ & $\mathrm{ca.10}$ & $\mathrm{ca.10}$ \\
Life span, week & 8 & 8 & 8 & 8 & 8 \\
Standard deviation $\left(\sigma_{\mathrm{v}}\right), \mathrm{mV}$ & 1.1 & 0.7 & 0.8 & 1.3 & 1.1 \\
Accuracy, \% & 99.8 & 99.7 & 99.1 & 99.3 & 99.2 \\
Trueness, \% & 98.9 & 98.2 & 98.3 & 99.2 & 99.1 \\
Repeatability $\left(\mathrm{CV}_{\mathrm{w}}\right), \%$ & 0.3 & 0.7 & 0.5 & 0.7 & 0.4 \\
Between day-variability $\left(\mathrm{CV}_{\mathrm{b}}\right), \%$ & 0.8 & 0.7 & 1.2 & 1.3 & 0.4 \\
\hline
\end{tabular}

\section{Accuracy and precision}

The agreement between the average concentration value obtained from 12 sets of potentiometric results for each sensor and the reference SMZ value obtained using the standard spectrophotometric method, was examined for the same SMZ solutions $(2.0 \mu \mathrm{g} / \mathrm{mL}$ of SMZ in $0.01 \mathrm{M}$ $\mathrm{Na}_{2} \mathrm{SO}_{4}$ at $\mathrm{pH}$ 7.0). The standard deviation and coefficient of variation were compared. A comparison between the proposed potentiometric sensors and the standard spectrophotometric method was done. Both methods were carried out using six portions of the same sample and each one in duplicate. The average mean SMZ value, standard deviation, and coefficient of variation are comparable (Table 1). This reflects the response repeatability of the sensors and confirms the accuracy of the proposed method.

Linearity, limit of detection (LOD) and limit of quantification (LOQ)

Linearity of the calibration graph, detection limit and quantification limit, were evaluated together with the linear regression analysis. The $\mathrm{SMZ}$ concentration was varied in the range from $10^{-6} \mathrm{M}$ to $10^{-2} \mathrm{M}$. Each concentration was measured in triplicate. From the calibration curves in Figure 2, the linear ranges is $7.8 \times 10^{-6}-10^{-2}(2.1-2783 \mu \mathrm{g} / \mathrm{mL}), 1.4 \times 10^{-5}-10^{-2}(3.8-2783 \mu \mathrm{g} / \mathrm{mL})$, 
$4.8 \times 10^{-6}-10^{-2}(1.3-2783 \mu \mathrm{g} / \mathrm{mL}), 2.6 \times 10^{-6}-10^{-2}(0.7-2783 \mu \mathrm{g} / \mathrm{mL})$ and $7.9 \times 10^{-6}-10^{-2}(2.2-2783 \mu \mathrm{g} / \mathrm{mL})$ for nitron/SMZ, aliquat-336, MgPC, MnPC and SnPC based membrane sensors, respectively. Detection limits calculated according to IUPAC guidelines ranged between 0.4 and $1.4 \mu \mathrm{g} / \mathrm{mL}$, respectively. Fixed or proportional bias of the proposed sensors was checked by a simple linear regression for the measured concentrations. The slopes of the regression lines were near the same to those of the ideal value of unity $\left(r^{2}=0.999\right)$. The present potentiometric method shows no systematic difference between the assessed and expected concentrations within the test range. The statistical analysis for linearity measurements is tabulated in Table 1.

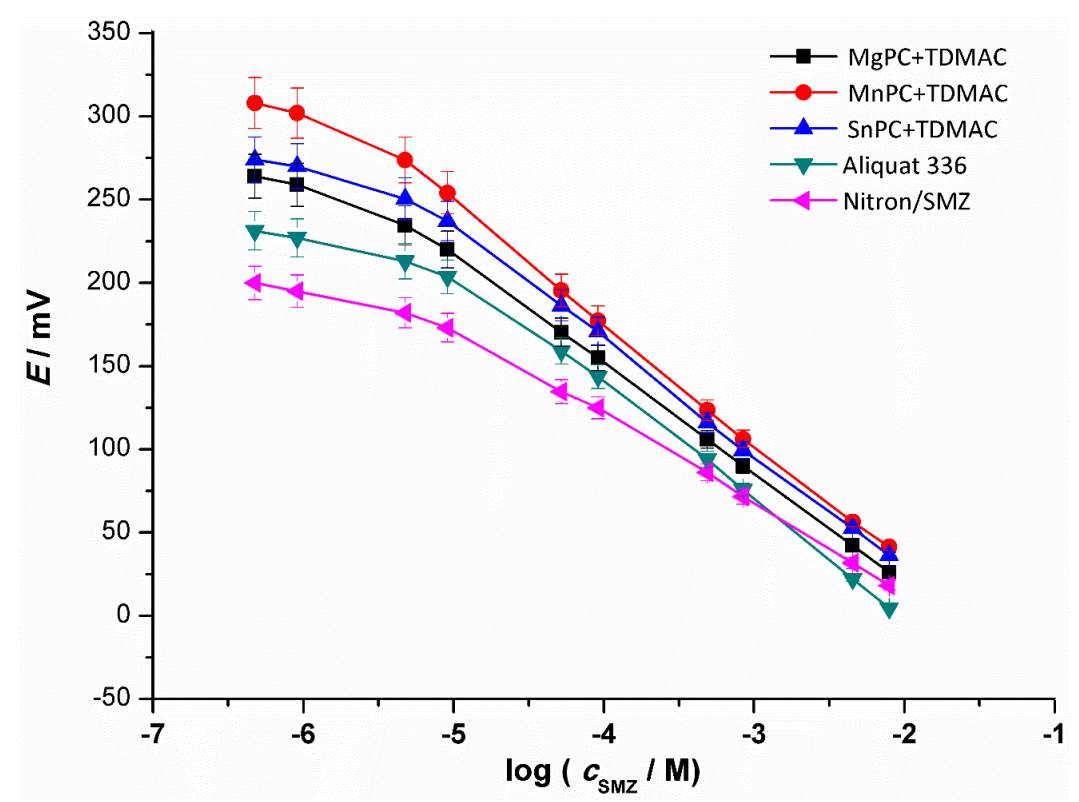

Figure 2. Potentiometric response of $\mathrm{SMZ}$ membrane based sensors using $0.01 \mathrm{M} \mathrm{Na}_{2} \mathrm{SO}_{4}$ at pH 7

\section{Specificity}

Selectivity of ion-potentiometric sensors is quantitatively related to the equilibrium at the interface between sample and sensor membrane. The impact of various common anions on the response of $S M Z$ sensors was investigated by measuring the selectivity coefficients (log $\left.K^{\text {Pot }}\right)$ of some species using the fixed solutions method [42]. The logarithmic values of log $K^{\text {Pot }}$ were calculated by Eq. (1)

$$
K_{\mathrm{A}, \mathrm{B}}^{\mathrm{Pot}}=a_{\mathrm{A}} /\left(a_{\mathrm{B}}\right)^{Z_{\mathrm{A}} / Z_{\mathrm{B}}}
$$

where $a_{B}$ is $1.0 \times 10^{-3} \mathrm{M}$ of the interfering species, $Z_{\mathrm{A}}$ and $Z_{\mathrm{B}}$ are the ionic charges of main and interfering ions and $a_{A}$ is the intersection of the extrapolated linear portions of the plot EMF versus the logarithm of SMZ concentration. In general, the values of log $K^{\text {Pot }}$ showed the extent of preferential SMZ interaction over different ionic species. Compounds that are commonly present in pharmaceuticals or biological samples were considered for this purpose. Potentiometric selectivity coefficient $\left(K_{\mathrm{A}, \mathrm{B}}^{\mathrm{Pot}}\right)$ data are illustrated in Table 2.

As shown in Table 2, sensors based on MgPC, MnPC and SnPC ionophores have a relatively high selectivity toward $\mathrm{SMZ}$ compared to other hydrophobic anions such as $\mathrm{ClO}_{4}$, salicylate, $\mathrm{I}^{-}$and $\mathrm{SCN}^{-}$ and other several common anions. The reason for the high selectivity of this electrode for the SMZ ion is thought to be due to a possible interaction of the anions with the central metal ion in the phthalocyanine ligand. 
Table 2. Potentiometric selectivity coefficients ( $\mathrm{K}^{\mathrm{Pot}}{ }_{S M Z, B}$ ) of SMZ membrane sensors in $10^{-2} \mathrm{M} \mathrm{Na}_{2} \mathrm{SO}_{4}$ at $\mathrm{pH}^{7.0}$

\begin{tabular}{lccccc} 
& \multicolumn{5}{c}{ Potentiometric selectivity coefficient } \\
\cline { 2 - 6 } Interfering ion & $\mathrm{MgPC}$ & $\mathrm{MnPC}$ & $\mathrm{SnPC}$ & Aliquat-336 & Nitron/SMZ \\
\hline $\mathrm{PO}_{4}{ }^{3-}$ & -3.8 & -3.9 & -2.6 & -2.8 & -2.8 \\
\hline $\mathrm{Cl}^{-}$ & -2.03 & -2.04 & -1.4 & -1.3 & -1.3 \\
\hline Salicylate & -1.04 & -1.29 & -0.3 & -0.1 & -0.1 \\
\hline $\mathrm{SCN}^{-}$ & -1.28 & -2.04 & -1.1 & +0.65 & -1.6 \\
\hline $\mathrm{I}^{-}$ & -2.04 & -2.32 & -0.9 & +0.67 & -1.1 \\
\hline $\mathrm{Citrate}^{-}$ & -3.84 & -3.87 & -2.7 & -2.9 & -2.7 \\
\hline $\mathrm{CH}_{3} \mathrm{COO}^{-}$ & -1.28 & -1.45 & -1.2 & -1.4 & -0.8 \\
\hline Tartarate & -2.3 & -4.47 & -3.4 & -2.5 & -3.6 \\
\hline $\mathrm{C}_{2} \mathrm{O}_{4}{ }^{2-}$ & -3.33 & -2.56 & -1.6 & -2.1 & -1.6 \\
\hline Ascorbate & -1.62 & -1.28 & -0.5 & -1.04 & -0.5
\end{tabular}

It has already been reported that metal complexes of phthalocyanines are able tocoordinate with some analyte anions at the fifth and sixth axial positions of the carrier molecule, producing selective interaction and inducing the selectivity sequence for anions which deviates from the Hofmeister series [43]. For sensors based on aliquat-336 and nitron/SMZ as ion exchangers, their selectivity behavior depends on the lipophilicity of the ion in the aqueous solution due to ion-exchange mechanism. So, these sensors exhibited severe interferences from highly lipophlic anions such as $\mathrm{ClO}_{4}{ }^{-}$, salicylate and $\mathrm{I}^{-}$ions. From all said above, we can conclude that selectivity coefficient values obtained for $\mathrm{Mg}$ (II)-, Mn(II)-and Sn(IV)- phthalocyanines based membrane sensors apparently differ from the Hofmeister selectivity pattern observed for nitron/SMZ and aliquat-336 based sensors.

\section{Ruggedness (Robustness)}

The sensitivity of the proposed method to variations of experimental conditions (temperature, $\mathrm{pH}$, and sample size) was tested. The ruggedness test was done using "Youden and Steiner partial factorial design" where eight replicate analyses were conducted, and three factors are varied and analyzed [44].

The effect of $\mathrm{pH}$ variation on the sensors potentials was studied for the SMZ solution of $10^{-3} \mathrm{~mol} \mathrm{~L}^{-1}$. The $\mathrm{pH}$ was adjusted by small additions of the concentrated $\mathrm{HCl}$ or $\mathrm{NaOH}$ solution and recorded by a combined glass-pH electrode. It was noticed that potential responses of the sensors are almost stable over the range of 6.5-8.0, with small potential variations within $\pm 2 \mathrm{mV}$. Variation of the concentration of SMZ samples over the range $10^{-5}-10^{-2} \mathrm{M}$ did not affect the accuracy by more than $1 \%$. Change of the temperature of the test solution from $18-25^{\circ} \mathrm{C}$ slightly affected the results. The simplest form of the Nernst equation is: $E=E_{0}+(0.065 / \mathrm{n}) \log c$. However, the $0.065 / \mathrm{n}$ part of the equation is a simplification of $2.303 \mathrm{RT} / \mathrm{nF}$. So, at $18{ }^{\circ} \mathrm{C}, 2.303 R T / F=0.060$ volts and upon increasing the temperature to $25^{\circ} \mathrm{C}$, this value goes up to 0.065 volts.

\section{Flow injection assembly}

FIA is an extraordinary branch in analytical chemistry which is operating in different techniques of analysis. FIA demonstrates many advantages like small volumes of samples that are quantified, fast operating, low cost, friendly to environment, applicability in the industrial field and easily automation. Four different sensors were constructed as previously mentioned to detect SMZ concentration under hydrodynamic operation.

A linear relationship between log [SMZ] concentrations and FIA signals were obtained over the concentration range of $10^{-6}-10^{-3} \mathrm{M}$ using $0.01 \mathrm{M} \mathrm{Na}_{2} \mathrm{SO}_{4}, \mathrm{pH} 7$ as shown in Fig. 3 . The optimum flow rate for measuring was chosen to be $3.5 \mathrm{~mL} / \mathrm{min}$. The sensors revealed a sub-Nernstian response 
with slopes of $-53.7,-39,-43.2$ and $-37 \mathrm{mV} /$ decade over a linear concentration range between $9.9 \times 10^{-5}, 10^{-5}, 1.1 \times 10^{-5}$ and $10^{-4} \mathrm{M}$ to $10^{-2} \mathrm{M}$, and detection limits of $17.5,2.78,2.78,13.94 \mu \mathrm{g} / \mathrm{mL}$ for the aliquat-336, MgPC, MnPc and Nitron/SMZ membrane-based sensors, respectively. General performance characteristics are shown in Table 3. The lower sensitivity of FIA measurements may be attributed to the small volume of the injectable sample, flow rate, and time taken for the sample to be reacted on the surface of the sensor. As shown in Table 3, the sample frequency/hour is 60, 46, 48 and 50 sample/h for aliquat-336, MgPC, MnPc and nitron/SMZ membrane-based sensors, respectively.
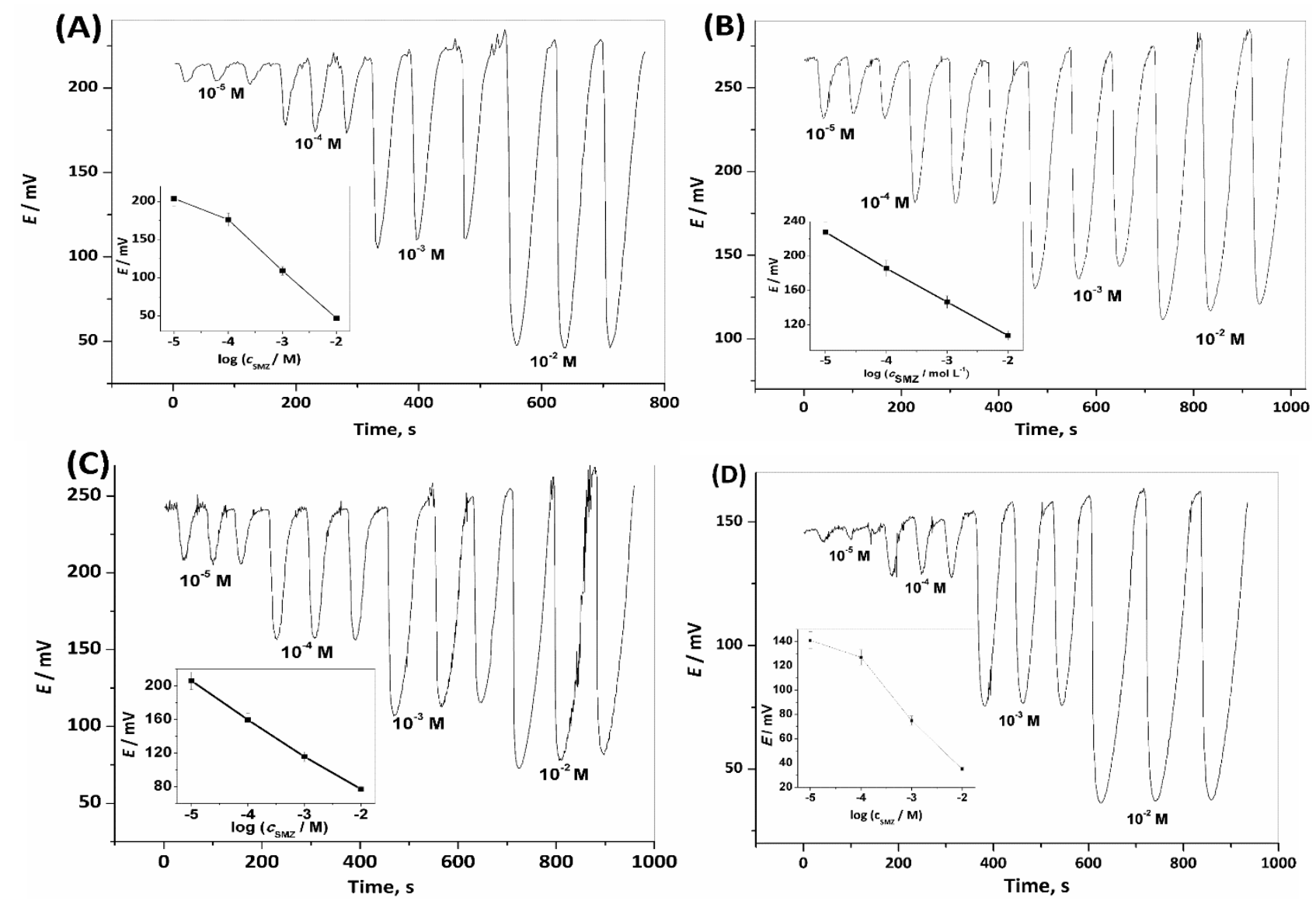

Figure 3. FIA signals for the evaluation of $S M Z$ in $0.01 \mathrm{M}$ carrier sodium sulphate solution $\mathrm{pH}$ 7.0, loop sample $100 \mathrm{\mu L}$, and flow rate $3.5 \mathrm{~mL} / \mathrm{min}$; (A) Aliquat-336; (B) MgPC; (C) MnPC; and (D) Nitron/SMZ membrane based sensors

Table 3. Performance characteristics of SMZ membrane sensors plasticized with o-NPOE under hydrodynamic mode (FIA) of operation in $10^{-2} \mathrm{M} \mathrm{Na}_{2} \mathrm{SO}_{4}$ buffer of $\mathrm{pH} 7.0$

\begin{tabular}{lcccc} 
& \multicolumn{3}{c}{ Sensor } \\
\cline { 2 - 5 } \multicolumn{1}{c}{ Parameter } & Aliquat-336 & MgPC & MnPC & Nitron/SMZ \\
\hline Slope, $\mathrm{mV} /$ decade & -53.7 & -39 & -43.2 & -37 \\
\hline Correlation coefficient ${ }^{\circledR}$ & -0.986 & -0.988 & -0.997 & -0.979 \\
\hline Linear range, $\mathrm{M}$ & $9.9 \times 10^{-5}-10^{-2}$ & $1.0 \times 10^{-5}-10^{-2}$ & $1.1 \times 10^{-5}-10^{-2}$ & $1.0 \times 10^{-4}-10^{-2}$ \\
\hline Detection limit, $\mu \mathrm{g} / \mathrm{mL}$ & 17.5 & 2.78 & 2.78 & 13.94 \\
\hline Life span, week & 8 & 8 & 8 & 8 \\
\hline Optimum flow rate, $\mathrm{mL} / \mathrm{min}$ & 3.5 & 3.5 & 3.5 & 3.5 \\
\hline Sample frequency, sample/h & 60 & 46 & 48 & 50 \\
\hline
\end{tabular}




\section{SMZ assessment}

To test the applicability of the proposed method using the proposed sensors for determining SMZ, natural matrices such as drug formulations, milk or chicken muscle samples were taken. Two commercial products containing SMZ, labeled $33.3 \mathrm{~g} / 100 \mathrm{~mL}$ were collected from local markets for veterinary treatments. Potentiometric determination of SMZ in triplicate under both static and hydrodynamic mode of operations showed results with an average recovery of 99.1 and $98.7 \%$ and a mean standard deviation of \pm 1.2 and $\pm 2.3 \%$ for both static and hydrodynamic mode of operations (Table 4). These data were compared with results obtained by UV-spectrophotometry [45]. An Ftest revealed that there is no significant difference between the means and variances of two sets of results. Quality control/quality assurance (QC/QA) of the method was tested by daily drug analysis over one month. $R$ and $X$ control charts [46] clearly indicated that all distribution measurements and range of assays data were under statistical control (lie between the warrant and control limits without any abnormalities).

Table 4. Potentiomeric determination of SMZ in pharmaceutical preparations using SMZ membrane sensors

\begin{tabular}{|c|c|c|c|c|c|c|c|c|c|c|c|}
\hline \multirow{4}{*}{$\begin{array}{l}\text { Commercial } \\
\text { products* }\end{array}$} & \multicolumn{11}{|c|}{ Found, $\mathrm{g} / 100 \mathrm{~mL}$} \\
\hline & \multicolumn{10}{|c|}{ Potentiometry } & \multirow{3}{*}{$\begin{array}{l}\text { Spectro- } \\
\text { metry }[45\end{array}$} \\
\hline & \multicolumn{2}{|c|}{ Aliquat-336 } & \multicolumn{2}{|c|}{ MgPC/TDMAC } & \multicolumn{2}{|c|}{ MnPC/TDMAC } & \multicolumn{2}{|c|}{ SnPC/TDMAC } & \multicolumn{2}{|c|}{ Nitron/SMZ } & \\
\hline & Batch & FIA & Batch & FIA & Batch & FIA & Batch & FIA & Batch & FIA & \\
\hline $\begin{array}{l}\text { Sulphadimidine } \\
\text { Injection** }\end{array}$ & $32.7 \pm 1.1$ & $31.8 \pm 0.9$ & $32.6 \pm 1.4$ & $31.7 \pm 1.4$ & $33.4 \pm 0.6$ & $31.8 \pm 0.3$ & $31.7 \pm 1.7$ & $33.7 \pm 0.1$ & $31 \pm 0.2$ & $35.9 \pm 0.9$ & $34 \pm 0.7$ \\
\hline $\begin{array}{l}\text { Sulphadimidine } \\
\text { Injection } * * *\end{array}$ & $31.8 \pm 0.9$ & $34.4 \pm 1.2$ & $32.6 \pm 0.7$ & $33.6 \pm 1.8$ & $33 \pm 1.2$ & $34.7 \pm 1.5$ & $32.2 \pm 1.6$ & $32.5 \pm 1.1$ & $33.4 \pm 0.2$ & $32.6 \pm 1.3$ & $33.7 \pm 0.4$ \\
\hline
\end{tabular}

The method was also tested for determining SMZ in milk and chicken muscles by spiking aliquots of different samples with the known standard of SMZ. The results showed an average recovery of $99.1 \%$ with a relative standard deviation of $\pm 0.8 \%$. Results obtained for determination of SMZ in milk and chicken muscle samples using batch and FIA are compared in Table 5.

Table 5. Assessment of SMZ in spiked samples with milk and chicken muscle using MnPC membrane-based sensor

\begin{tabular}{lccc}
\hline \multirow{2}{*}{ Sample } & Spiked, $\mu \mathrm{g} / \mathrm{mL}$ & \multicolumn{2}{c}{${ }^{*}$ Found, $\mu \mathrm{g} / \mathrm{mL}$} \\
\cline { 2 - 4 } Cow milk & 0.5 & $0.47 \pm 0.05$ & FIA \\
\cline { 2 - 4 } & 5 & $4.2 \pm 0.2$ & $4.1 \pm 0.5$ \\
\cline { 2 - 4 } Chicken muscles & 10 & $9.6 \pm 0.7$ & $9.3 \pm 0.3$ \\
\cline { 2 - 4 } & 0.5 & $0.42 \pm 0.04$ & - \\
\cline { 2 - 4 } & 0.75 & $0.68 \pm 0.07$ & - \\
\hline & 1 & $0.93 \pm 0.06$ & - \\
\hline
\end{tabular}

*Average of 5 measurements

\section{Conclusions}

Novel, simple and low cost potentiometric sensors were developed, characterized and used for static and continuous quantification of sulfamethazine drug. Automatic determination of SMZ using a flow-through system coupled with a potentiometric detector proved to be an advantageous method over many other analytical methods. Determinations of SMZ can be accomplished within a wide concentration range, regardless of the samples colors and turbidity. In addition, increased sensitivity provides improved precision, high sampling rates, low consumption of sample volume and better reproducibility. The results obtained in this work suggest that this methodology could be applied for rapid and accurate analysis of SMZ in different complex matrices. The sensors were 
utilized for SMZ determination in different pharmaceutical formulations in addition to chicken muscles and milk samples at an input rate of < 40 samples/hour. No interferences are caused by most anions that are normally present in these matrices. The results favorably compare with data obtained by the standard spectrophotometric method.

\section{References}

1. M. Franek, V. Kolar, A. P. Deng, S. Crooks, Food and Agricultural Immunology 11 (1999) 339-349.

2. N. T. Crosby, Determination of Veterinary Residues in Food, Ellis Horwood, NewYork, 1991.

3. N. A. Botsoglou, D. J. Fletouris, Drug Residues in Foods: Pharmacology, Food Safety and Analysis, Marcel Dekker, New York, pp.1194, 2001.

4. C. Hartig, T. Storm, M. Jekel, Journal of Chromatography A 854 (1999) 163-173.

5. Saganuwan, A. Saganuwan, Animal Research International 3 (2006) 457-460.

6. A. C. Tella, O. M. Olabemiwo, G. K. Obiyenwa, M. O. Salawu, African Scientist 11 (2010) 189-193.

7. D. D. Holland, S. E. Katz, Journal Association of Official Analytical Chemists 74 (1991) 784-789.

8. M. T. Combs, S. Boyd, M. Khorassani, L. T. Taylor, Agricultural and Food Chemistry 45 (1997) 1779-1783.

9. D. P. Schwartz, Journal Association of Official Analytical Chemists 65 (1982) 701-705.

10. J. H. Park, Korean Journal of Animal Science 41 (1999) 129-134.

11. V. Gaudin, M. L. Pavy, Journal of AOAC International 82 (1999) 1316-1320.

12. G. A. Baxter, M. C. O'Connor, S. A. Haughey, S. R. H. Crooks, C. T. Elliott, Analyst 124 (1999) 1315-1318.

13. H. Yang, West China Journal of Pharmaceutical Science 14 (1999) 238-241.

14. S. J. Stout, W. A. Steller, A. J. Manuel, M. O. Poeppel, A. R. daCunha, Journal Association of Official Analytical Chemists 67 (1984) 142-144.

15. V. B. Reeves, Journal of Chromatography B 723 (1999) 127-137.

16. B. Chiavarino, M. E.Crestoni, A. D. Marzio, S. Fornarini, Journal of Chromatography B: Biomedical Sciences and Applications 706 (1998) 269-277.

17. R. K. Munns, J. E. Roybal, Journal Association of Official Analytical Chemists 65 (1982) 1048-1053.

18. F. Belliardo, Journal of Apicultural Research 20 (1981) 44-48.

19. M. Petz, Zeitschrift Fur Lebensmittel-Untersuchung Und -Forschung 176 (1983) 289-293.

20. E. D. McGary, Analyst 111 (1986) 1341-1342.

21. G. Stoev, A. Michailova, Journal of Chromatography A 871 (2000) 37-42.

22. B. C. Grande, M. S. G. Falcón, M. R. Comesaña, J. S. Gándara, Journal of Agricultural Food Chemistry 49 (2001) 3145-3150.

23. U. R. Cieri, Journal Association of Official Analytical Chemists 59 (1976) 56-59.

24. R. L. Smallidge, E. J. Kentzer, K. R. Stringham, E. H. Kim, C. Lehe, R.W. Stringham, E. C. Mundell, Journal Association of Official Analytical Chemists 71 (1988) 710-717.

25. J. D. Weber, M. D. Smedley, Journal Association of Official Analytical Chemists 72 (1989) 445-447.

26. J. D. Weber, M. D. Smedley, Journal of AOAC International 76 (1993) 725-729.

27. G. Bartolucci, G. Pieraccini, F. Villanelli, G. Moneti, A. Triolo, Rapid Communication of Mass Spectrometry 14 (2000) $967-973$.

28. P. Edder, A. Cominoli, C. Corvi, Trav. Chim. Aliment. hyg. 88 (1997) 554-569.

29. D. Jonas, G. Knupp, H. Pollmann, Archiv Fur Lebensmittelhygiene 34 (1983) 138-141.

30. R. K. Buick, N. M. Greer, C. T. Elliott, Analyst 125 (2000) 95-396.

31. S. S. M. Hassan, M. H. Eldesouki, Journal Association of Official Analytical Chemists 64 (1981) 1158-1163.

32. L. Chen, Y. Xu, L. Sun, J. Zheng, J. Dai, C. Li, Y. Yan, Analytical Letters 51(13) (2018) 2099-2113

33. L. Urzúa, M. Pérez-Ortiz, A. Álvarez-Lueje, Journal of the Chilean Chemical Society 63(1) (2018) 3914-3917

34. A. H. Kamel, S. A. A. Almeida, M. G. F. Sales, F. T. C. Moreira, Analytical Sciences 25 (2009) 365-371.

35. J. Yuan, S. Yao, Talanta 58 (2002) 641-648.

36. Q. Fu, X. He, H. Suo, J. Wang, C. Zhao, Journal of Near Infrared Spectroscopy 20 (2012) 397-406.

37. S. S. M. Hassan, E. M. Elnemma, W. H. Mahmoud, A. H. K. Mohamed, Journal of Applied Electrochemistry 36 (2006) 139-146.

38. A. H. Kamel, H. E. M. Sayour, Electroanalysis 21 (2009) 2701-2708.

39. S. S. M. Hassan, A. H. Kamel, H. Abd El-Naby, Journal of Chinese Chemical Society 61 (2014) 295-302.

40. IUPAC, Analytical Chemistry Division, Commission on Analytical Nomenclature, Pure Applied Chemistry 66 (1994) $2527-2536$.

41. J. K. Taylor, Quality Assurance of Chemical Measurements (CRC Press, Florida, 1987).

42. Y. Umezawa, K. Umezawa, H. Sato, Pure Applied Chemistry 67 (1995) 507-518.

43. Z. L. Jun, C. W. Xiao, Y. Ruo, G. L. Hui, Q. Y. Ru, Analyst 119 (1994) 1363-1366.

44. L. P. van Reeuwijk, V. J. G. Houba, Guidelines for Quality Management in Soil and Plant Laboratories, Food and Agriculture Organization of the United nations (FAO) Rome 74 (1998) 95-97.

45. N. Yongnian, Q. Zhengbao, S. Kokot, Chemometrics and Intelligent Laboratory Systems 82 (2006) 241-247.

46. W. Funk, V. Dammann, G. Donnevert, Quality Assurance in Analytical Chemistry, VCH, New York, 1995.

C2019 by the authors; licensee IAPC, Zagreb, Croatia. This article is an open-access article distributed under the terms and conditions of the Creative Commons Attribution license

(http://creativecommons.org/licenses/by/4.0/) 